\title{
Diagnosis and Treatment of Peritonsillar Abscess with Single Enhanced Computed Tomography
}

\author{
Kudamo Song ${ }^{1}$, Jun Lee ${ }^{1}$, So Young $\mathrm{Choi}^{2}$, and Myoung Su Choi ${ }^{1}$ \\ ${ }^{1}$ Departments of Otolaryngology-Head and Neck Surgery, ${ }^{2}$ Radiology, Eulji University Medical Center, \\ Eulji University School of Medicine, Daejeon, Korea
}

조영제 사용 후의 영상만을 이용한 편도주위농양 진단과 치료

송커다모 ${ }^{1} \cdot$ 이 준 $^{1} \cdot$ 최소영 ${ }^{2} \cdot$ 최명수 $^{1}$

을지대학교 의과대학 이비인후과학교실, ${ }^{1}$ 영상의학교실 ${ }^{2}$

Received November 13, 2017

Revised January 15,2018

Accepted January 18, 2018

Address for correspondence

Myoung Su Choi, MD

Department of Otolaryngology-

Head and Neck Surgery,

Eulji University Medical Center,

Eulji University School of Medicine,

95 Dunsanseo-ro, Seo-gu,

Daejeon 35233, Korea

Tel $+82-42-611-3129$

Fax $+82-42-611-3136$

E-mail mschoi@eulji.ac.kr
Background and Objectives Diagnostic features of peritonsillar abscess are an asymmetrically enlarged palatine tonsil with peripheral rim enhancement and central low density in the post-contrast computed tomography $(\mathrm{CT})$. Although it is necessary to differentiate tumorous conditions of tonsils to compare pre- and post-contrast CT, pre-contrast CT may be less useful in the diagnosis of peritonsillar abscess. This study aims to evaluate of the efficacy of single post-contrast CT for diagnosis and treatment of peritonsillar abscess.

Subjects and Method We retrospectively compared 29 patients with peritonsillar abscess, who were diagnosed by single post-contrast $\mathrm{CT}$, with 36 patients diagnosed by pre- and postcontrast CT to determine the success rates of pus drainage and hospital days. Additionally, two otorhinolaryngologists made a judgment of abscess presence for sixty randomly mixed CT images of peritonsillar abscess or tonsillitis with pre- and post-contrast CT or single post-contrast CT.

Results There were no significant differences in the success rate of drainage $(p=0.622)$ and hospital days ( $p=0.504$ ) between groups with/without pre-contrast CT. Abscess presence was judged by raters with/without pre-contrast CT. Inter-rater agreement value (Cohen's kappa) was $0.825(p<0.01)$.

Conclusion Single post-contrast CT of peritonsillar abscess may be a good alternative for diagnosis and treatment and may reduce unnecessary exposure to radiation.

Korean J Otorhinolaryngol-Head Neck Surg 2018;61(2):99-102

Key Words Computed tomography $\cdot$ Contrast media $\cdot$ Peritonsillar abscess $\cdot$ Sensitivity Specificity.

\begin{abstract}
서 론
편도주위농양은 구개 편도의 급성 염증이 주위 결체 조직 으로 이루어진 편도 주위 공간에 파급되어 농양을 형성하는 질환이다. 환자는 발열과 지속적인 인후통, 연하곤란을 호소

This is an Open Access article distributed under the terms of the Creative Commons Attribution Non-Commercial License (http://creativecommons.org/licenses/by-nc/4.0) which permits unrestricted non-commercial use, distribution, and reproduction in any medium, provided the original work is properly cited.
\end{abstract}

하게 되며, 조기에 진단하지 못하거나 적절한 치료를 시행하 지 않으면, 기도폐색이나, 종격동염으로 진행할 수 있어 주의 를 요하는 질환이다. ${ }^{1}$ 편도주위농양의 진찰소견은 주로 일측 편도 주위의 발적과 종창이 관찰되며, 구개수는 농양 반대측 으로 편위되어 있으며, 입안에서 악취가 나기도 한다. 일반적 으로 편도주위농양이 의심되면 주사침으로 의심 부위를 흡 인해 농을 확인하여 진단할 수 있다. 최근에는 computed tomography(CT)를 시행하거나, 방사선에 노출되는 피해를 줄 

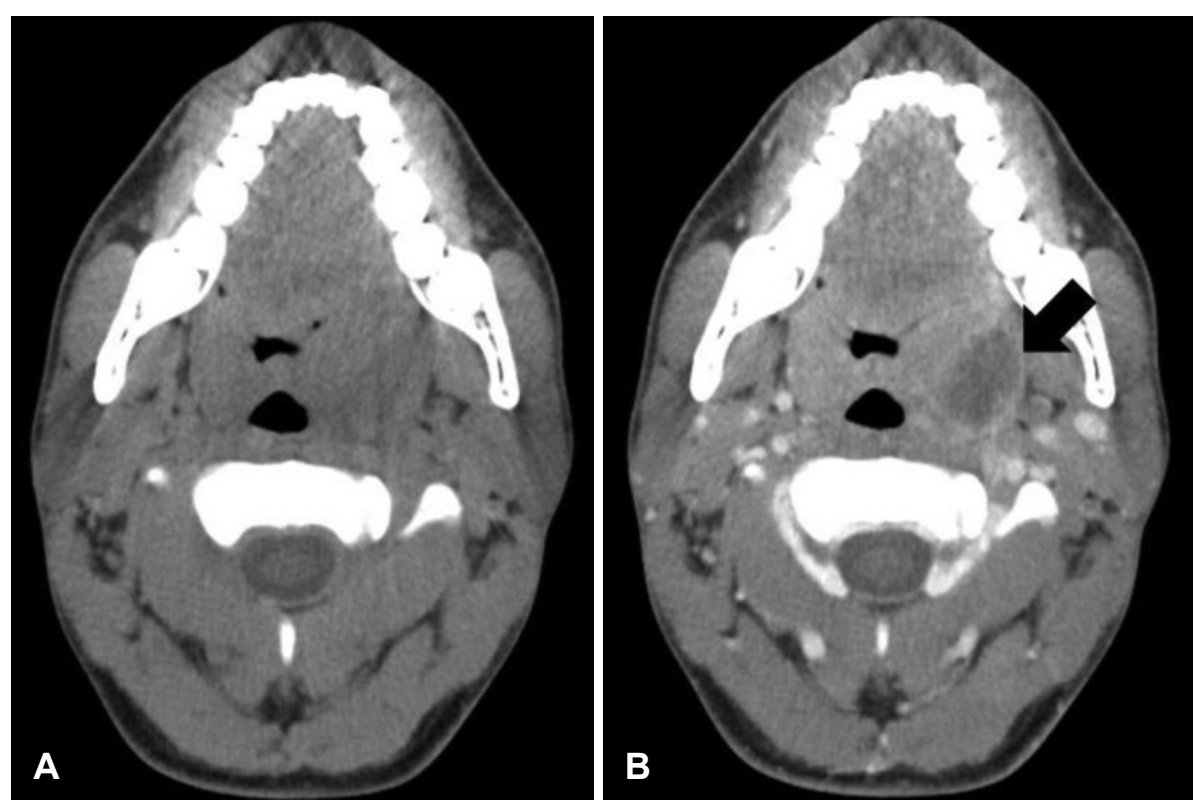

Fig. 1. Computed tomographic findings of peritonsillar abscess. Precontrast axial view (A). Post-contrast axial view (B). Black arrow indicates peritonsillar abscess pocket.

이기 위해서 초음파를 이용하여, 편도주위농양의 여부를 영 상학적으로 먼전 진단한 후, 이 부위를 주사침으로 흡인하거 나 절개배농하기도 한다. ${ }^{2-6)}$

편도주위농양 진단 시, 경부 CT는 일반적으로 조영제를 사 용하기 전 일 회 촬영을 하며, 같은 부위에 조영제를 사용하 고 한 번 더 촬영을 한다(Fig. 1). 조영 전후의 영상을 비교하여, 조영 후 영상에서 편도 주위 공간 환형의 띠에 조영 증강(rim enhancement)이 보이면서, 내부에 저음영(central low density) 을 보일 때 편도주위농양으로 진단할 수 있다(Fig. 1). ${ }^{7)}$ 다중채 널 CT는 과거와 달리, 최근 의료영상저장전송시스템(picture archiving and communication system, PACS)과 연동되며, 축 상, 시상, 관상면으로 영상을 재건할 수 있어서 판독과 치료에 많은 도움을 주고 있다. 따라서 이러한 CT와 PACS의 도입으 로, 조영 전 영상이 과거와 달리 편도주위농양을 진단하는 데 크게 필요하지 않을 수 있다는 가정하에, 조영 후의 영상만을 이용하여 편도주위농양을 진단하고 치료하는 데 유용성을 알아보고자 하였다.

\section{대상 및 방법}

2016년 10월부터 12월까지 편도주위농양으로 의심되어 입 원하여 조영 후의 경부 CT만을 촬영하여 진단하고 치료한 환 자 29명을 2015년 10월부터 12월까지 조영 전후의 경부 CT 를 촬영하여 진단하고 치료했던 환자 36명과 치료 성적 등을 후향적으로 비교 분석하였다. 이 연구는 본원 IRB 심의를 받 아 진행하였다(EMC-2017-11-002). 촬영한 CT는 이비인후과 전문의나 영상의학과 전문의가 판독하여, 편도 주위 공간 내
부에 저음영의 저류가 보이면서 이를 둘러싸는 환형의 띠의 조 영 증강이 저명하게 관찰된 경우에는 편도주위농양으로 영 상학적 판단을 시행하였으며, 절개배농을 시행해 농을 확인 하여 최종적으로 편도주위농양으로 진단하였다. CT상 편도 주위 공간에 균질한 연조직 음영의 종창을 보이나 명백한 농 양이 관찰되지 않을 경우는 영상학적으로 편도주위염으로 판정하였다. 또한 CT상 농양이 저명하지 않거나, 치아 보철 등에 음영 판정이 어려운 경우에는 절개배농 시 농을 확인한 경우에만 편도주위농양으로 진단하였으며, 절개배농 시 농을 확인하지 못한 경우에는 편도주위염으로 판정하였다. CT상 확인된 농양 부위를 절개배농하여 육안으로 농을 확인한 경 우를 비교하고, 입원기간과 치료 후 합병증 등의 치료결과를 후향적으로 분석하였다. 절개배농을 한 후 배액관을 삽입하 였으며, 배액관은 방사능표지자가 피복되어 있는 실리콘 튜 브를 재단하여 농양 부위에 삽입하고, 편도 주위의 종창이 호전되어 배액관을 통해서 농이 스며 나오지 않으면 다음 날 제거하였다. CT상 농양으로 확인되었으나 절개배농 시 농양 을 육안으로 확인하지 못한 경우에는 절개 부위를 1 2일간 개방한 후 농의 배출 여부를 지속적으로 관찰하였다. 편도주 위농양으로 입원한 모든 환자는 첫날 dexamethasone $5 \mathrm{mg}$ (Huons, Seongnam, Korea)을 근육주사 시행하였으며, 광범 위 항생제 Augmentin 3.6 g(Ilsung, Seoul, Korea)을 하루 3 회 나누어 정주하였으며, 입원 중 균동정 결과가 나오면 감수 성이 있는 항생제에 맞게 변경하였다. Augmentin에 부작용이 있는 경우에는 경험적으로 Ceftriaxone $2 \mathrm{~g}$ (Boryung, Seoul, Korea)을 하루 1회, Flagyl 1.5 g(Albogen Korea, Seoul, Korea)을 병합요법으로 하루 3회 나누어 정주하였다. 


\section{$\mathrm{CT}$ 를 이용한 편도주위농양 판정}

편도주위농양으로 확인된 35 명 환자의 경부 CT와, 농양이 없는 편도선염이나 편도 주위 봉와직염 환자의 경부 CT 25 개를 무작위로 섞은 60 장의 영상을, 이비인후과 수련의 2 명 에게(경력 2년, 경력 3년) 농양 여부를 판정하게 하였다. 경력 2년의 수련의에게는 조영 전후의 CT 영상을 모두 이용하게 하였으며, 경력 3년의 수련의에게는 조영 후의 CT만을 이용 하여 편도주위농양 여부를 판정하게 하였다. 두 명의 평가자 의 민감도와 특이도를 구하고 판정의 일치도를 구하였다.

\section{통계분석}

통계분석은 SPSS 18.0(SPSS Inc., Chicago, IL, USA)을 사용하였으며, 조영 전후의 영상을 이용한 것과 조영 후의 영상을 이용하여 치료한 편도주위농양의 비교 시에, 두 군의 비교는 카이제곱, Fisher's exact test, t-test를 이용하였으며, 편도주위농양의 영상을 판독하는 실험에서는 두 그룹의 일 치도를 카파값을 구하여 비교하였다. $p$ 값은 0.05 이하를 유 의하다고 정하였다.

\section{결 과}

조영 전후의 영상 모두를 이용하여 치료한 36명 환자는 남 녀가 각각 23명, 13 명이었으며, 평균연령은 29세였고, 36명 중 에서 32명(88.9\%)은 명백한 농을 배출시킬 수 있었다(Table 1). 치료기간도 평균 5.9 일 소요되었으며 합병증은 없었다. 조 영 후의 영상을 이용하여 치료한 29명 환자는 남녀가 각각 16 명, 13 명이었으며, 평균연령은 34세였고, 29명 중 26명 (89.7\%)에서 농을 배출시킬 수 있었다(Table 1). 치료기간은 평균 6일이었으며, 합병증은 없었다. 조영 전후를 같이 사용 한 그룹과 조영 후의 영상만을 이용하여 치료한 그룹 사이에 는 나이, 성별, 입원기간, 농양 배출 성공에 유의한 차이를 보 이지 않았다(Table 1).

두 명의 수련의가 한 명은 조영 전후를 이용해서, 나머지 한 명은 조영 후만의 영상을 이용해서 편도주위농양을 진단

Table 1. Comparison of treatment outcome in peritonsillar abscess

\begin{tabular}{lccc}
\hline \multicolumn{1}{c}{ Parameter } & Pre \& post CT & Only post CT & p-value \\
\hline Patients & 36 & 29 & \\
Male/female & $23 / 13$ & $16 / 13$ & $0.323^{*}$ \\
Age (years) & $29.1 \pm 12.1$ & $34.1 \pm 10.5$ & $0.076^{\dagger}$ \\
Pus drainage & $32(88.9 \%)$ & $26(89.7 \%)$ & $0.622^{\ddagger}$ \\
Hospital days & $5.9 \pm 1.2$ & $6.0 \pm 0.9$ & $0.504^{\dagger}$ \\
Complication & 0 & 0 & \\
\hline
\end{tabular}

*chi-square test, tt-test, „Fisher's exact test
한 결과, 두 명의 일치도는 카파값이 0.825 로 나와서 상당한 일치도를 보였다 $(p<0.01)$. 두 명의 수련의는 35 개의 편도주 위농양 중에서 조영 전후를 이용한 수련의는 33 개를 농양이 있다고 판정하였으며, 조영 후의 영상만을 이용한 수련의는 34 개를 농양이 있다고 판정하였다(Table 2). 조영 전후의 영 상을 이용한 수련의는 편도염 또는 편도주위염 영상 25 개 중 에서 21 개를 농양이 없다고 판정하였고, 조영 후의 영상을 이용한 수련의는 23 개를 농양이 없다고 판정하였다(Table 2). 조영 전후의 영상을 이용한 수련의의 민감도와 특이도는 $94.3 \%$ 와 $84.0 \%$ 이며, 조영 후의 영상만을 이용한 수련의는 97.1\%와 92.0\%였다(Table 2).

\section{고 찰}

최근 의료진단 분야에서 $\mathrm{CT}$ 의 유용성은 점차 증가하여 진단에 필수적인 경우로 포함되는 범위가 점점 많아졌다. 건 강보험 심사평가원 자료에 따르면, CT 촬영건수는 2006년도 에 2411327건에서 2014년도 9841215건으로 해마다 가파르 게 증가하고 있다. CT 이외에도 양전자방출 전산화단층촬영 장치, 감마카메라, 혈관조영장치, 유방촬영장치, 방사선치료 장비 등, 의료 진단과 치료 분야에서 방사선의 사용은 더욱 넓어지고 있다. 방사선 피폭량을 나타내는 단위는 밀리시버 트 $(\mathrm{mSv})$ 로 표시하는데, 우리나라 국민이 1년 동안 생활 속에 서 피폭되는 방사선량은 $3.6 \mathrm{mSv}$ 로 알려져 있다. ${ }^{8}$ 일반 흥부 X선은 0.01 0.1 mSv 정도가 피폭되는 데 반해, 두경부 CT는 $2 \mathrm{mSv}$, 흥부나 복부 CT는 8 10 mSv 정도가 피폭된다. ${ }^{9}$

증가하는 방사선 사용량을 줄이려는 노력은 여러 분야에 서 시도되고 있다. CT 검사를 받는 환자들의 방사선량을 의 무적으로 기록, 관리하는 제도가 시행되었으며, 타 병원에서 동일 부위에 시행한 $\mathrm{CT}$ 의 중복 촬영을 자제하고 있다. 또한 저선량 CT를 이용하여 조사량을 줄이면서도 적절한 해상도 를 얻을 수 있는 프로토콜이 많이 개발되고 연구되어 왔

Table 2. Diagnosis of peritonsillar abscess with/without pre-contrast CT

\begin{tabular}{lcc}
\hline \multicolumn{1}{c}{ Parameter } & Pre \& post CT & Only post CT \\
\hline $\begin{array}{l}\text { Abscess (+) judgement/ } \\
\text { with PTA }\end{array}$ & $33 / 35$ & $34 / 35$ \\
$\begin{array}{l}\text { Abscess (-) judgement/ } \\
\text { without PTA }\end{array}$ & $21 / 25$ & $23 / 25$ \\
Sensitivity (\%) & 94.3 & 97.1 \\
Specificity (\%) & 84.0 & 92.0 \\
PP-value (\%) & 89.2 & 94.4 \\
NP-value (\%) & 91.3 & 95.8
\end{tabular}

PTA: peritonsillar abscess, PP-value: positive predictive value, NP-value: negative predictive value 
다. ${ }^{10-12)}$ 이비인후과 영역에서는 측두골 CT나 부비동개구단 위 CT는 주로 골성 구조를 분석하는 데 이용되기 때문에, 조 영제 사용 없이 1 회 방사선 노출만으로 영상을 얻고 있다. 그 러나 조영제를 사용하는 경부 CT는 조영 전후의 영상을 비 교하여 조영 정도의 차이를 평가하기 때문에 조영 전 $\mathrm{CT}$ 영 상을 통상적으로 같이 시행하고 있어, 조영 전 CT에 비해 2 배의 방사선 피폭을 받게 된다. 종양성 질환의 감별에는 조영 전후의 비교는 필수적이다. 그러나 종양성 질환과는 달리, 감 염성 편도 질환 같은 편도주위농양은 조영 전 영상의 유용성 이 떨어질 수 있다.

또한 단순 편도주위농양이 의심될 때에는 CT를 바로 시행 하는 것보다는, 환자의 병력과 철저한 이학적 검사를 통해서 의심되는 편도 주변 부위를 주사침으로 흡인하여 농을 확인 해 보는 것이 중요하다. 여러 번 주사침으로 흡인하여도 농을 확인하지 못하거나, 환자의 협조가 어렵거나, 개구장애가 심 해서 이학적 검사를 충분히 시행하기 어려운 경우, 이학적 검 사상 편도주위농양이 인접 심경부 공간으로 진행이 의심되는 상황에서 조영제를 사용하는 CT나 초음파를 시행하는 것도 불필요한 방사선 피폭이나 검사를 줄일 수 있는 방법이다.

이번 연구에서 조영 전 영상이 없는 경우에도, 편도주위농 양의 진단이나 치료에 차이가 없음을 보여주고 있다. 이번 연 구에서 CT 진단에는, 경력 2 3년의 이비인후과 수련의를 대 상으로 하였다. 전문의가 아닌 수련의의 경우에도 편도주위 농양 진단의 민감도는 $94 \%$ 이상으로 나왔으며, 특이도도 $84 \%$ 이상으로 비교적 높게 나왔다. 편도주위농양은 드물지 않아 많이 접해 볼 수 있으며, 특징적인 CT 영상 소견 때문 에 이비인후과 수련을 받는 수련자라면 비교적 쉽게 진단할 수 있는 질환이다. 다만, 편도 내부에 생긴 국소적인 저음영 까지도 편도주위농양으로 진단하는 경향을 보여서, 민감도 는 비록 높았지만, 특이도가 민감도보다 떨어지는 경향을 보 였다. 이비인후과 전문의의 경우에는 CT 진단 시 거의 민감 도와 특이도가 $100 \%$ 에 육박하기 때문에 이번 연구에 참여 시키지는 않았다.

$\mathrm{CT}$ 의 높은 진단률에도 불구하고 방사선 노출이라는 피해 를 줄이기 위해서, 초음파를 이용하여 편도주위농양을 진단 하는 연구가 많이 보고되어 왔다. ${ }^{2-6)}$ 국내에서는 $\mathrm{Kim}$ 등 $^{2}$ 이 구강내 초음파와 칼러도플러를 이용하여 민감도 $91.7 \%$, 특 이도 $100 \%$ 로 보고한 바 있다. 구강 대신에 경부를 통한 초음 파로 편도주위농양을 진단하는 연구에서, 44 명의 편도주위 농양 진단에 민감도 $94.7 \%$, 특이도 $83.3 \%$ 로 경구강과 거의 비슷한 결과를 보고하였다. ${ }^{3)} \mathrm{CT}$ 와 초음파의 편도주위농양 진단의 정확도를 비교한 연구에서는 CT가 민감도 $100 \%$, 특 이도 $75 \%$ 이며, 경구강 초음파는 민감도 $89 \%$, 특이도 $100 \%$ 로
보고하여, $\mathrm{CT}$ 가 초음파보다 민감도가 좀 더 높지만, 경구강 초음파도 상당한 정도의 유용성을 보인다고 보고하였다. ${ }^{13)}$

이번 연구에 포함되지 않았지만 본원에서 자체적으로 시행 한 결과, 부인두농양, 후인두농양 등의 인후두 염증성 질환에 서도, 조영 후의 CT 영상만으로도 조영 전후의 두 가지 CT 영상과 견주어 크게 진단적 효과에 차이가 나지 않았다. 최근 에는 CT와 PACS 시스템이 연동이 되어 CT로 찍은 영상을 컴퓨터 모니터에서 축상면 영상 이외에도 관상, 시상면으로 재 구성하여 보고자 하는 부위를 3차원적으로 파악할 수 있어, 절개배농에도 많은 도움을 주고 있다. 또한 조영 후 CT 영상 이라도 PACS 내에서 대조(contrast)를 조정하면, 조영효과 를 사라지게 하고 뼈 음영을 부각할 수도 있어, 마치 조영 전 영상을 찍은 것과 거의 비슷한 효과를 얻을 수 있다.

이번 연구를 통해서 조영 후 CT 단독으로도 편도주위농양 진단과 치료에 고식적인 CT와 견주어 차이가 없음을 보여주 었으며, 이를 통해서 방사선 피폭을 절반으로 줄일 수 있었다.

\section{REFERENCES}

1) Herzon FS, Martin AD. Medical and surgical treatment of peritonsillar, retropharyngeal, and parapharyngeal abscesses. Curr Infect Dis Rep 2006;8(3):196-202.

2) Kim SM, Cho JJ, Kim JY, Huh HB, Hur CH, Lee MW. Diagnosis of peritonsillar abscess using gray scale image and color dopplerimage of intraoral ultrasonography. Korean J Otolaryngol-Head Neck Surg 1998;41(9):1180-4.

3) Nam SY, Park BJ, Kim HJ, Lee KS. Clinical usefulness of neck ultrasonography in peritonsillar abscess. Korean J OtorhinolaryngolHead Neck Surg 2008;51(12):1134-9.

4) Strong EB, Woodward PJ, Johnson LP. Intraoral ultrasound evaluation of peritonsillar abscess. Laryngoscope 1995;105(8 Pt 1):779-82.

5) Rehrer M, Mantuani D, Nagdev A. Identification of peritonsillar abscess by transcutaneous cervical ultrasound. Am J Emerg Med 2013;31(1):267.e1-3.

6) Haeggström A, Gustafsson O, Engquist S, Engström CF. Intraoral ultrasonography in the diagnosis of peritonsillar abscess. Otolaryngol Head Neck Surg 1993;108(3):243-7.

7) Capps EF, Kinsella JJ, Gupta M, Bhatki AM, Opatowsky MJ. Emergency imaging assessment of acute, nontraumatic conditions of the head and neck. Radiographics 2010;30(5):1335-52.

8) Lee YK. Level of radiation dose in university hospital noninsured private health screening programs in Korea. Environ Health Toxicol 2016;31:e2016007.

9) Sodickson A, Baeyens PF, Andriole KP, Prevedello LM, Nawfel RD, Hanson R, et al. Recurrent CT, cumulative radiation exposure, and associated radiation-induced cancer risks from $\mathrm{CT}$ of adults. Radiology 2009;251(1):175-84.

10) Shieh $Y$, Bohnenkamp M. Low-dose CT scan for lung cancer screening: clinical and coding considerations. Chest 2017;152(1):204-9.

11) Yun SJ, Ryu CW, Choi NY, Kim HC, Oh JY, Yang DM. Comparison of low- and standard-dose CT for the diagnosis of acute appendicitis: a meta-analysis. AJR Am J Roentgenol 2017;208(6):W198-207.

12) Villa L, Giusti G, Knoll T, Traxer O. Imaging for urinary stones: update in 2015. Eur Urol Focus 2016;2(2):122-9.

13) Scott PM, Loftus WK, Kew J, Ahuja A, Yue V, van Hasselt CA. Diagnosis of peritonsillar infections: a prospective study of ultrasound, computerized tomography and clinical diagnosis. J Laryngol Otol 1999;113(3):229-32. 